\title{
AVALIAÇÃO DO SULFATO DE ALUMÍNIO, POLICLORETO DE ALUMÍNIO E CLORETO FÉRRICO NO TRATAMENTO DE ÁGUA BRUTA DO RIO SANTO ANASTÁCIO
}

\section{EVALUATION OF ALUMINIUM SULFATE, ALUMINIUM POLYCHORIDE AND FERRIC CHLORIDE ON RAW WATER TREATMENT OF SANTO ANASTÁCIO RIVER}

José Augusto Alves Pimentaㄹ ; José Wilson dos Santos Ferreira ${ }^{1}$; Rafael Henrique Garcez Nicolau' ${ }^{1}$; Danielle Elis Garcia Furuya ${ }^{1}$; Leila Maria Sotocorno e Silva²; Gilberto José da Paz Júnio

\author{
${ }^{1}$ Discentes dos Cursos de Engenharia Civil e Engenharia Ambiental e Sanitária da \\ UNOESTE \\ e-mail: josepimenta37@gmail.com \\ ${ }^{2}$ Docentes do Curso de Engenharia Civil da UNOESTE \\ e-mail: eng.gilbertopaz@gmail.com
}

RESUMO - A água bruta pode conter contaminantes que em elevadas concentrações podem apresentar sérios riscos à saúde humana. Deste modo, o estudo teve como objetivo comparar a eficiência dos coagulantes Sulfato de Alumínio, Policloreto de Alumínio (PAC) e Cloreto Férrico, no tratamento de água bruta do Rio Santo Anastácio (SP), nas etapas de coagulação, floculação e sedimentação, utilizando Jar-Test. Inicialmente determinou-se dosagens adequadas dos coagulantes com base nos parâmetros cor, turbidez, $\mathrm{pH}$ e alcalinidade e com resultados obtidos, avaliou-se fósforo, nitrato, nitrito, dureza total, DQO, DBO, sólidos totais, bactérias heterotróficas, coliformes totais e E-coli para determinação do coagulante mais eficaz. Todos atenderam aos parâmetros físico-químicos, estabelecidos pela Portaria no 2914/2011 do Ministério da Saúde, porém o sulfato de alumínio com concentração $70 \mathrm{mg} \cdot \mathrm{L}^{-1}$ obteve a maior taxa de remoção nos parâmetros biológicos, sendo o mais eficiente para o tratamento da água bruta do rio Santo Anastácio.

Palavras-chave: coagulação; floculação; sedimentação; coagulantes.

Recebido em: 09/08/2017

Revisado em: 19/09/2017

Aprovado em: 05/10/2017
ABSTRACT - Raw water may contain contaminants which at high concentrations may pose a serious risk to human health. Thus, the objective of this study was to compare the efficiency of the coagulants aluminum sulphate, aluminum polychloride (PAC) and ferric chloride, in the treatment of raw water of the Santo Anastácio River (SP), in the coagulation, flocculation and sedimentation stages, using Jar- Test. Initially, adequate dosages of the coagulants were determined based on the parameters color, turbidity, $\mathrm{pH}$ and alkalinity. Phosphorus, nitrate, nitrite, total hardness, COD, BOD, total solids, heterotrophic bacteria, total coliforms and E-coli were evaluated from the results obtained to determinate which was the most effective coagulant. All of them all 
meet the physical-chemical parameters standards established by Decree no 2914 of the Ministry of Health, however, aluminum sulfate with a concentration of $70 \mathrm{mg} . \mathrm{L}^{-1}$ obtained the highest removal rate in the biological parameters, being the most efficient in the treatment, of raw water of the Santo Anastácio River.

Keywords: coagulation; flocculation; sedimentation; coagulants. 


\section{INTRODUÇÃO}

Devido à crescente densidade demográfica em grandes partes das bacias hidrográficas e do elevado uso e ocupação do solo em zonas rurais, muitas vezes há significantes aumentos no processo de erosão bem como na emissão de efluentes. Esses fatores, além de afetar diretamente a qualidade da água, estão acarretando em tratamentos cada vez mais dispendiosos para que ela se torne potável (VANACÔR, 2005).

Apesar de conter substâncias indispensáveis à manutenção da vida, a água, devido sua característica de solvente universal, pode carregar consigo elementos químicos e microrganismos prejudiciais à saúde do consumidor (BERNARDO et al. 2002; RICHTER; NETO, 2007).

A fim de atender aos padrões regulamentados pela Portaria no 2914 de 2011 do Ministério da Saúde, a água a ser destinada ao abastecimento deve passar por processos de tratamento que visam adequar seus parâmetros físicos, químicos, biológicos.

Dentre as etapas do tratamento existe o processo de coagulação, que consiste na adição de um produto químico (coagulante) sobre uma dispersão coloidal, resultando na desestabilização das partículas através da redução das forças que tendem a manter as mesmas afastadas (BERNARDO; DANTAS, 2005; BAUMANN, 1971).
Os coagulantes são geralmente constituídos de sais de alumínio e ferro, sendo comumente utilizados o Sulfato de Alumínio, o Policloreto de Alumínio (PAC) e o Cloreto Férrico, em virtude da eficiência na remoção de partículas orgânicas e inorgânicas, suspensas ou coloidais.

Devido à importância do Rio Santo Anastácio (SP), responsável por parte do abastecimento de água no município de Presidente Prudente - SP, este estudo teve como objetivo comparar, através de ensaios em escala de bancada, a eficiência dos coagulantes Sulfato de Alumínio, Policloreto de Alumínio e Cloreto Férrico no tratamento da água bruta desse manancial, por meio da avaliação de parâmetros físicos, químicos e biológicos, sendo eles: cor, turbidez, alcalinidade, pH, fósforo, nitrato, nitrito, dureza total, Demanda Química de Oxigênio (DQO), Demanda Bioquímica de Oxigênio (DBO), sólidos totais, bactérias heterotróficas, coliformes totais e E-coli e, deste modo, definir o coagulante que se apresentou mais eficaz no processo de potabilização da água.

\section{METODOLOGIA}

O trabalho fundamentou-se na realização de ensaios em escala de bancada com equipamento Jar-test, associados à avaliação das características físicas, químicas e biológicas da água, para obtenção das 
melhores eficiências de coagulação dos coagulantes: cloreto férrico, sulfato de alumínio e policloreto de alumínio, sendo ela realizada em duas etapas.

A Etapa 1 se constituiu na avaliação preliminar dos parâmetros de cor, turbidez, $\mathrm{pH}$ e alcalinidade, a fim de obter as concentrações que expressam melhores eficiências de coagulação, floculação e sedimentação, para cada um dos coagulantes (Figura 1). Ressalta-se que as dosagens e comportamentos foram avaliados individualmente.
Uma vez obtidos os resultados das dosagens ótimas de cada um deles, foi realizada a Etapa 2 (Figura 2), onde os parâmetros físicos, químicos e biológicos da água foram avaliados, por meio de ensaios de alcalinidade, condutividade, cor, DBO, dureza, DQO, fósforo, nitrato, nitrito, oxigênio dissolvido, $\mathrm{pH}$, sólidos totais, turbidez, coliformes totais, E-coli e bactérias heterotróficas, antes e depois do processo de tratamento.

Figura 1. Fluxograma das atividades da Etapa 1.

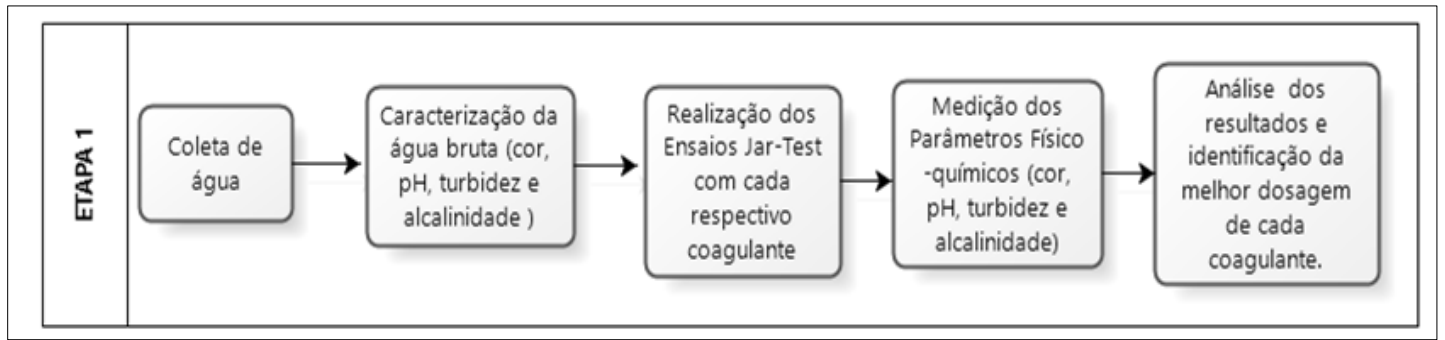

Fonte: (Autores, 2016).

Figura 2. Fluxograma das atividades da Etapa 2.

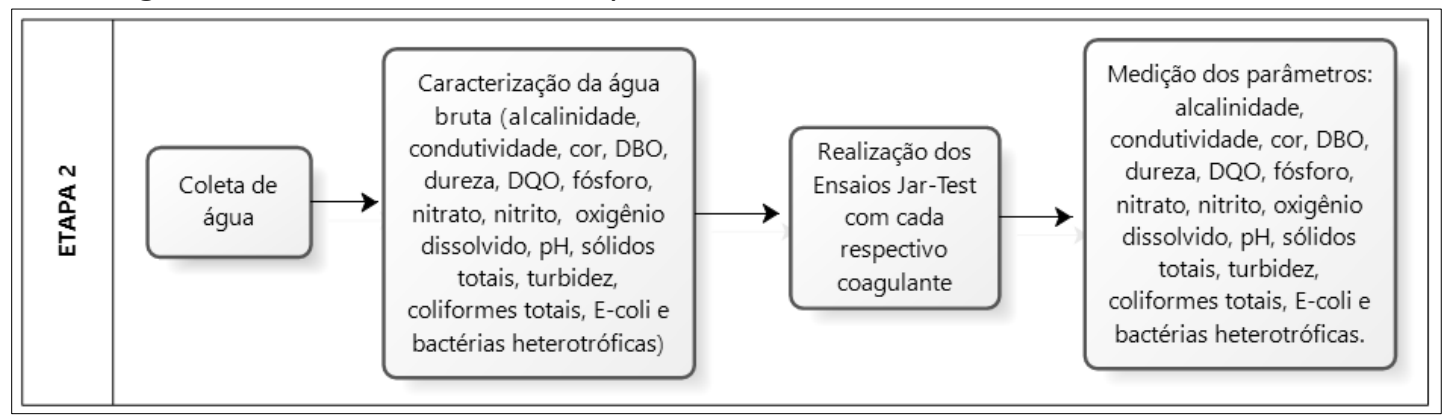

Fonte: (Autores, 2016)

\subsection{Caracterização do Manancial de Estudo}

O rio Santo Anastácio (SP), está localizado a sudoeste do extremo oeste paulista, entre os meridianos de $51^{\circ}$ e $53^{\circ}$, e entre os paralelos de $21^{\circ} 45^{\prime}$ e $22^{\circ} 45^{\prime}$ na
Unidade de Gerenciamento de Recursos Hídricos do Pontal do Paranapanema UGRHI-22, sua bacia abriga as cidades de Presidente Bernardes, Presidente Venceslau, Marabá Paulista, Álvares Machado, Santo 
Anastácio, Presidente Epitácio e Presidente Prudente. (MATOS, 2014).

A bacia possui área de drenagem de $1.965 \mathrm{Km}^{2}$, o curso principal do Rio apresenta $155 \mathrm{Km}$ de extensão e deságua na margem esquerda do Rio Paraná, no município de Presidente Epitácio (CETESB, 1991). Dispondo-se paralelamente aos rios do Peixe e Paranapanema, o rio Santo Anastácio tem sua cabeceira de drenagem entre as altitudes de 500 a 480 metros (SUDO, 1980).

Dibieso (2013) complementa que a ocupação do solo na bacia se caracteriza principalmente por pastagens, culturas como milho, cana de açúcar e café e as áreas urbanizadas se localizam predominantemente no setor norte e noroeste da bacia.

\subsection{Coleta das Amostras}

As coletas foram realizadas em um único ponto, localizado na margem do rio a jusante da represa que era anteriormente utilizada pela empresa Companhia Industrial de Conservas Alimentícias (CICA), por cerca de 30 anos. Hoje ela é utilizada pela Companhia de Saneamento do Estado de São Paulo (SABESP) para coleta de água para parte do abastecimento de Presidente Prudente - SP. A Figura 3 representa o local a margem do Rio Santo Anastácio onde foram realizadas as coletas.
Figura 3. Ponto de coleta da água.

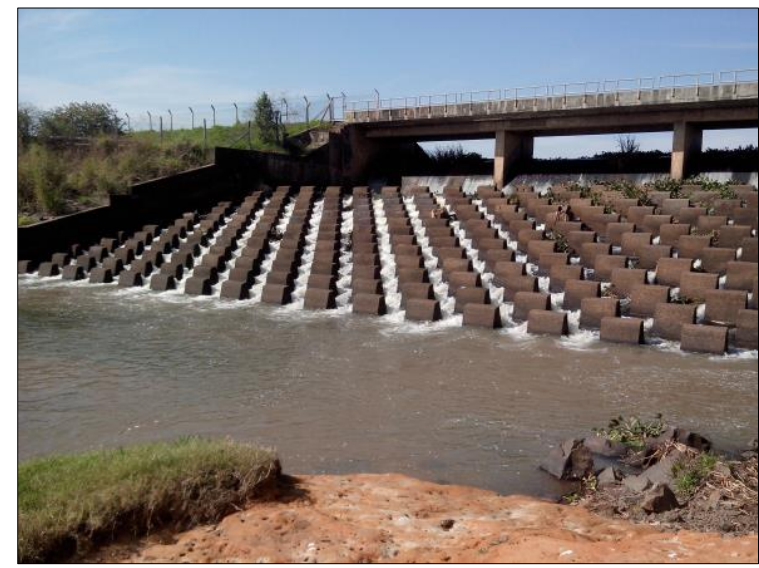

Fonte: (Autores, 2016).

Para o armazenamento da água, foram utilizados quatro galões, com capacidade de 40 litros cada, sendo as amostras coletadas nos dias 19, 29 e 30 de junho de 2016 para utilização nos ensaios com cloreto férrico, sulfato de alumínio e PAC, compreendidos na primeira etapa da pesquisa. Por fim, no dia 18 de julho de 2016 foi coletada a amostra utilizada na segunda etapa. Vale ressaltar que todos os ensaios foram feitos no Laboratório de Análise de Águas da Universidade do Oeste Paulista (UNOESTE).

\subsection{Parâmetros avaliados}

Foram analisados parâmetros físicos, químicos e biológicos da água, parâmetros estes recomendados pela Instrução Técnica DPO $n^{\circ} 006$ do DAEE (Departamento de Águas e Energia Elétrica) e Portaria MS $\mathrm{n}^{\circ}$ 2914/2011 (BRASIL, 2011). Na Tabela 1 estão os parâmetros físico-químicos considerados, 
as técnicas e métodos; todas as análises foram realizadas em duplicata.

Os ensaios microbiológicos também foram feitos em duplicada no Laboratório de Análise de Água da UNOESTE, e tomaram como base a metodologia descrita por Santana (2014) e Standard Methods for the Examination of Water and Wastewater (2005).
Nestes, foram quantificados coliformes totais, E-coli e bactérias heterotróficas. A técnica utilizada foi a filtração em membrana, tendo como meio de cultura o Chromocult Coliforme Agar $^{\circledR}$ da Merck como substrato cromogênico.

Tabela 1. Técnicas analíticas de realização dos ensaios físico-químicos.

\begin{tabular}{ccc}
\hline Parâmetro & Técnica & Referência \\
\hline \hline Alcalinidade $^{(\mathrm{a})}$ & Titulação & $2320 \mathrm{~B}$ \\
\hline Condutividade $^{(\mathrm{b})}$ & Potenciométrico & $2510 \mathrm{~B}$ \\
\hline Cor $^{(20)}$ & Espectrofotometria & $2120 \mathrm{C}$ \\
\hline DBO & Teste de 5 dias & $5210 \mathrm{~B}$ \\
\hline Dureza & Titulação & $2340 \mathrm{C}$ \\
\hline DQO & Método Colirimétrico de Refluxo Fechado & $5220 \mathrm{D}$ \\
\hline Fósforo & Espectrofotometria & $4500-\mathrm{P} \mathrm{D}$ \\
\hline Nitrato & Redução com cádmio & $4500-\mathrm{NO}_{3} \mathrm{~B}$ \\
\hline Nitrito & Espectrofotometria & $4500-\mathrm{NO}_{2} \mathrm{~B}$ \\
\hline Turbidez & Nefelométrica & $2130 \mathrm{~B}$ \\
\hline Oxigênio & Método com eletrodos de Membrana & $4500-\mathrm{O} \mathrm{G}$ \\
Dissolvido & Potenciométrico & $4500-\mathrm{H}^{+} \mathrm{B}$ \\
\hline pH & Secagem a $100^{\circ} \mathrm{C}$ & $2540 \mathrm{~B}$ \\
\hline Sólidos Totais & &
\end{tabular}

Fonte: Adaptado de APHA (2005).

O meio é preparado a partir da dissolução de 26,5g de Agar em 1 litro de água destilada, com auxílio de banho maria, logo após, volumes de $5 \mathrm{ml}$ de água foram distribuídos em placas Petri, devidamente esterilizadas, que após a solidificação do meio de cultura, são mantidas em refrigeração até o momento de uso (MERCK, 2013).

Para quantificação dos microrganismos foi realizada a filtração de uma amostra de $100 \mathrm{ml}$, ou de sua diluição, numa membrana esterilizada com porosidade de retenção de $0,45 \mu \mathrm{m}$; após a filtração, a membrana foi depositada no interior de uma placa Petri, preparada como descrito anteriormente e levada para a incubadora na temperatura de $36^{\circ} \mathrm{C}$, por um período de 24 horas. Em seguida, foi realizada a contagem das Unidades Formadoras de Colônias (UFC/100ml).

As colônias de coloração vermelho salmão identificam os coliformes totais, as colônias azuis/pretas o grupo E-coli, 
enquanto que as amarelas as bactérias heterotróficas.

\subsection{Ensaio de Coagulação, Floculação e} Sedimentação

Após a coleta de água foram realizados os ensaios em escala de bancada de coagulação, floculação, seguido de sedimentação, nos quais foram utilizados os coagulantes químicos cloreto férrico, sulfato de alumínio e policloreto de alumínio (PAC).

A metodologia de escolha das dosagens a serem aplicadas foi empírica, já que não se conhecia o comportamento das amostras quando submetidas aos coagulantes, sendo assim, adotou-se dosagens com escala de $10 \mathrm{mg} \cdot \mathrm{L}^{-1}$ em todos os jarros, e com base nos resultados obtidos refinou-se as dosagens, de acordo com as melhores eficiências observadas. Para tal, foi utilizado o equipamento Jar-test, empregado na simulação, em escala de bancada, dos processos de coagulação, floculação e sedimentação com gradientes de mistura controlados. O modelo é o JT-103 da marca Milan (Figura 4), composto de 6 jarros de acrílico transparente com a capacidade de 2 litros cada, e com gradiente de velocidade variando de $20^{-1} \mathrm{~s}$ a $120^{-1} \mathrm{~s}$.
Figura 4. Equipamento Jar-test JT-103, marca Milan.

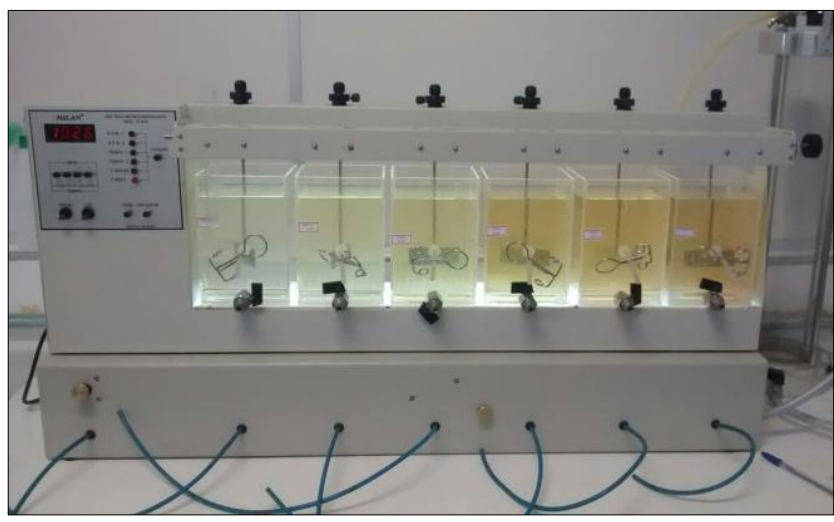

Fonte: (Autores, 2016).

Para realização dos ensaios, foram adotados os tempos e gradientes de coagulação, floculação e sedimentação apresentados na Tabela 2. O tempo de sedimentação variou em função do coagulante utilizado, como será discutido no item 4.1.2.

Tabela 2. Parâmetros de controle operacional utilizados.

\begin{tabular}{l|c}
\hline $\begin{array}{l}\text { Tempo de mistura rápida } \\
\text { (Tmr) }\end{array}$ & $3 \mathrm{~min}$ \\
\hline $\begin{array}{l}\text { Gradiente de velocidade de } \\
\text { mistura rápida (Gmr) }\end{array}$ & $120 \mathrm{~s}^{-1}$ \\
\hline Tempo de floculação (Tfloc) & $17 \mathrm{~min}$ \\
\hline $\begin{array}{l}\text { Gradiente de velocidade de } \\
\text { floculação (Gfloc) }\end{array}$ & $35 \mathrm{~s}^{-1}$ \\
\hline $\begin{array}{l}\text { Tempo de sedimentação } \\
\text { (Tsed) }\end{array}$ & $\begin{array}{c}* \mathrm{a} \\
16 \mathrm{~min}\end{array}$ \\
\hline
\end{tabular}

*Nota: Tsed de 16 min utilizado nos ensaios com sulfato de alumínio.

Fonte: (Autores, 2016).

A respeito dos coagulantes químicos, o Cloreto Férrico $\left(\mathrm{FeCl}_{3} 6 \mathrm{H}_{2} \mathrm{O}\right)$ foi preparado a partir de uma solução padrão com densidade de 1,406 e concentração de $887,2 \mathrm{~g} \cdot \mathrm{L}^{-1}$, resultando em uma solução com $20 \mathrm{~g} \cdot \mathrm{L}^{-1}$. A 
mesma quantidade de solução foi obtida a partir do Sulfato de Alumínio $\left(\mathrm{Al}_{2}\left(\mathrm{SO}_{4}\right)_{3}\right.$ $14 \mathrm{H}_{2} \mathrm{O}$ ), com solução padrão apresentando densidade de 1,340, concentração de $700,8 \mathrm{~g} \cdot \mathrm{L}^{-1}$ e com o Policloreto de Alumínio $\left(\mathrm{Al}_{n}(\mathrm{OH})_{m} \mathrm{Cl}_{3 n-m}\right)$, de solução padrão com densidade de 1,225 e concentração de $359 g \cdot L^{-1}$.

\section{RESULTADOS}

Os resultados foram divididos em duas partes, sendo a primeira relacionada a Etapa 1 do trabalho, em que se determinou as dosagens mais eficientes para os coagulantes, com base nos parâmetros: cor, $\mathrm{pH}$, alcalinidade e turbidez. A segunda parte contém a Etapa 2, em que se apresenta os valores das investigações físico-químicas e biológicas para os pontos de melhor eficiência dos coagulantes para a água bruta do rio Santo Anastácio.

\subsection{Etapa 1}

Foram realizados ensaios com os três coagulantes para obtenção das dosagens de maior eficiência. Inicialmente variou-se as concentrações na escala de $10 \mathrm{mg} \cdot \mathrm{L}^{-1} \mathrm{em}$ cada jarro, ao decorrer dos ensaios, baseando-se na eficiência de tratamento dos coagulantes, foram usadas várias concentrações de coagulante, refinando-as para atingir a dosagem ideal.
Adverte-se para o fato de que, em locais onde há ausência de dados de alcalinidade, foi devido a limitação da metodologia para valores de $\mathrm{pH}$ da água menores que 4,5 e os valores de cor adotados como 0,9 foram em amostras onde a medição no equipamento mostrou cor aparente menor que $1 \mathrm{uH}$.

$\mathrm{Na}$ Tabela 3 são apresentadas as características da água bruta do manancial, coletada em diferentes dias, sendo denominadas águas de estudo 1, 2 e 3 (AE-1, $A E-2$ e $A E-3$ ) e utilizadas com os coagulantes cloreto férrico, sulfato de alumínio e PAC, respectivamente.

Tabela 3. Águas brutas utilizadas nos ensaios com os coagulantes: Cloreto férrico, Sulfato de alumínio e Policloreto de Alumínio.

\begin{tabular}{|c|c|c|c|}
\hline \multirow{2}{*}{ Parâmetros } & \multicolumn{3}{|c|}{ Águas de Estudo } \\
\hline & AE-1 & AE-2 & AE-3 \\
\hline $\mathrm{pH}$ & 7,4 & 7,4 & 7,2 \\
\hline Turbidez (uT) & 23,5 & 15,1 & 9,43 \\
\hline $\begin{array}{l}\text { Alcalinidade } \\
\left(\mathrm{mg} \mathrm{CaCO}_{3} \mathrm{~L}^{-1}\right)\end{array}$ & 71,54 & 141,34 & 140,6 \\
\hline Cor (uH) & 21 & 23 & 18 \\
\hline
\end{tabular}

Fonte: (Autores, 2016).

\subsubsection{Cloreto Férrico}

Com o cloreto férrico, foram realizadas ao todo quatro ensaios jar-test. A Figura 4 apresenta os resultados do primeiro e segundo ensaio, ao passo que as Figuras 5 e 
6 retratam os resultados do terceiro e quarto ensaio, respectivamente.

Figura 4. Gráfico das variações de $\mathrm{pH}$, cor, alcalinidade e turbidez do ensaio jar-test com cloreto férrico nas concentrações $10 \mathrm{mg} \cdot \mathrm{L}^{-1} \mathrm{a}$ $110 \mathrm{mg} \cdot \mathrm{L}^{-1}$ em intervalos de $10 \mathrm{mg} \cdot \mathrm{L}^{-1}$.

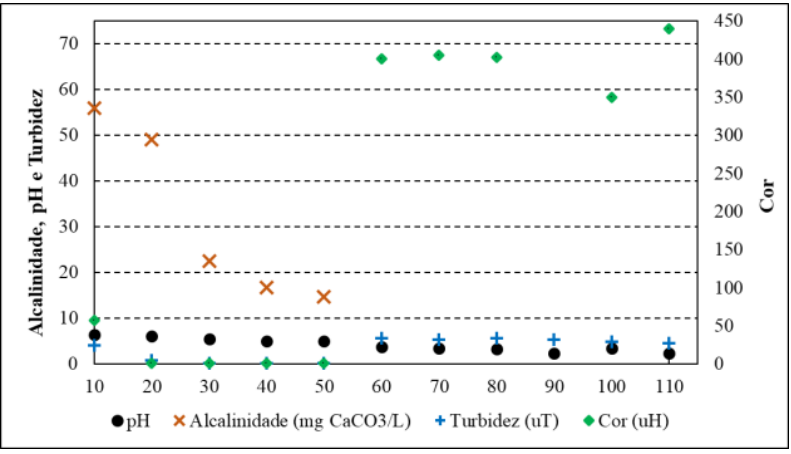

Fonte: (Autores, 2016).

Figura 5. Gráfico das variações de $\mathrm{pH}$, cor, alcalinidade e turbidez do ensaio jar-test com cloreto férrico nas concentrações: $25 \mathrm{mg} . \mathrm{L}^{-1}$, $35 \mathrm{mg} \cdot \mathrm{L}^{-1}, 45 \mathrm{mg} \cdot \mathrm{L}^{-1}, 47,5 \mathrm{mg} \cdot \mathrm{L}^{-1}, 52,5 \mathrm{mg} \cdot \mathrm{L}^{-1} \mathrm{e}$ $55 \mathrm{mg} \cdot \mathrm{L}^{-1}$.

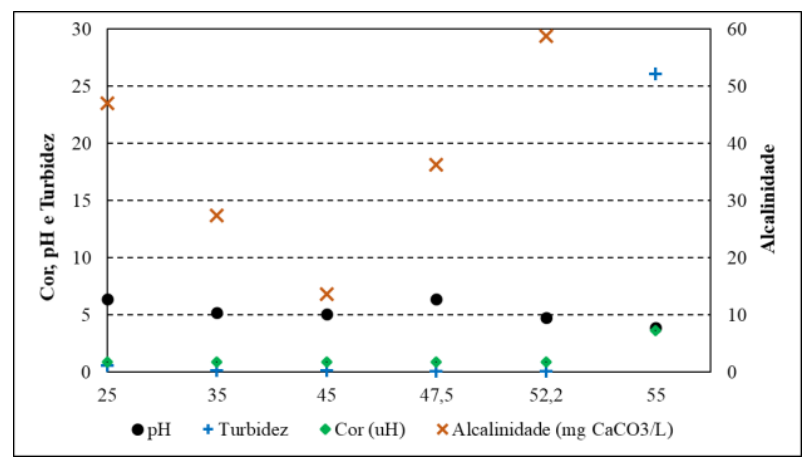

Fonte: (Autores, 2016).
Figura 6. Gráfico com pH, cor, alcalinidade e turbidez do jar-test com cloreto férrico nas concentrações $47 \mathrm{mg} . \mathrm{L}^{-1}, 48 \mathrm{mg} \cdot \mathrm{L}^{-1}, 49 \mathrm{mg} . \mathrm{L}^{-1}$, $51 \mathrm{mg} \cdot \mathrm{L}^{-1}, 52 \mathrm{mg} \cdot \mathrm{L}^{-1}, 53 \mathrm{mg} \cdot \mathrm{L}^{-1}$.

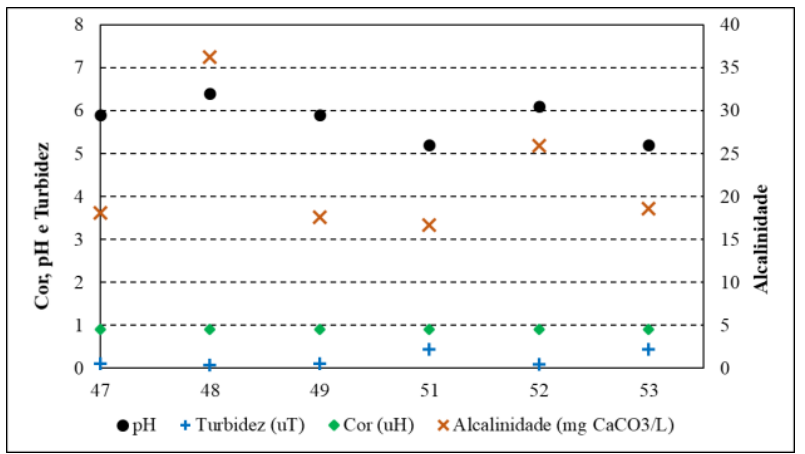

Fonte: (Autores, 2016).

\subsubsection{Sulfato de Alumínio}

Durante a realização do primeiro ensaio, observou-se que as partículas formadas ao fim do Tsed (8 minutos) ainda não haviam se sedimentado, logo, foi adotado para este coagulante o Tsed de 16 minutos, indicando, portanto, que elas eram menos densas.

Com sulfato de alumínio foram realizados ao todo três ensaios, as Figuras 7 e 8 apresentam os resultados destes. 
Figura 7. Gráfico das variações de pH, cor, alcalinidade e turbidez do ensaio jar-test com sulfato de alumínio nas concentrações $10 \mathrm{mg} \cdot \mathrm{L}^{-1}$ a $120 \mathrm{mg} \cdot \mathrm{L}^{-1}$ com intervalo de $10 \mathrm{mg} \cdot \mathrm{L}^{-1}$.

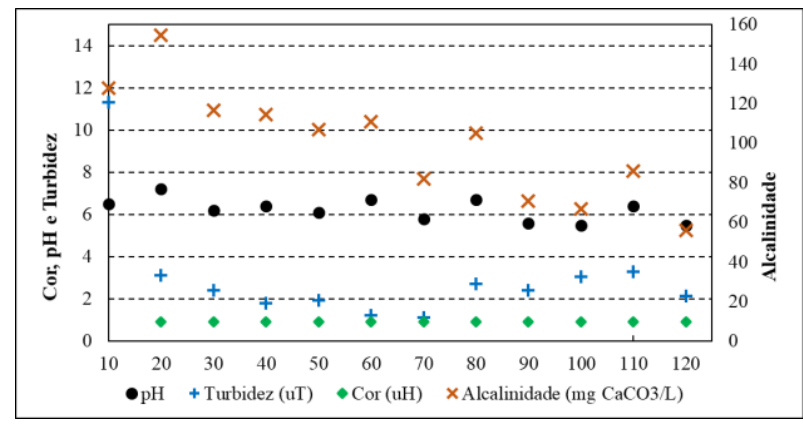

Fonte: (Autores, 2016).

Figura 8. Gráfico das variações de $\mathrm{pH}$, cor, alcalinidade e turbidez do ensaio jar-test com sulfato de alumínio nas concentrações $62 \mathrm{mg} \cdot \mathrm{L}^{-1}, \quad 64 \mathrm{mg} \cdot \mathrm{L}^{-1}, \quad 66 \mathrm{mg} \cdot \mathrm{L}^{-1}, \quad 68 \mathrm{mg} \cdot \mathrm{L}^{-1}$, $72 \mathrm{mg} \cdot \mathrm{L}^{-1}, 74 \mathrm{mg} \cdot \mathrm{L}^{-1}$.

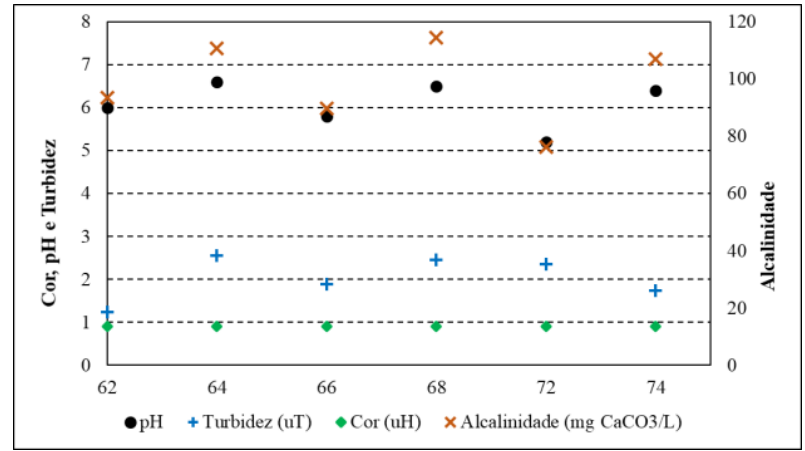

Fonte: (Autores, 2016).

\subsubsection{Policloreto de Alumínio (PAC)}

Com uso do PAC foram realizadas ao todo dois ensaios, cujos dados são apresentados nas Figuras 8 e 9.
Figura 9. Gráfico das variações de pH, cor, alcalinidade e turbidez do ensaio jar-test com PAC nas concentrações $10 \mathrm{mg} \cdot \mathrm{L}^{-1}$ a $120 \mathrm{mg} \cdot \mathrm{L}^{-1}$ em intervalos de $10 \mathrm{mg} \cdot \mathrm{L}^{-1}$.

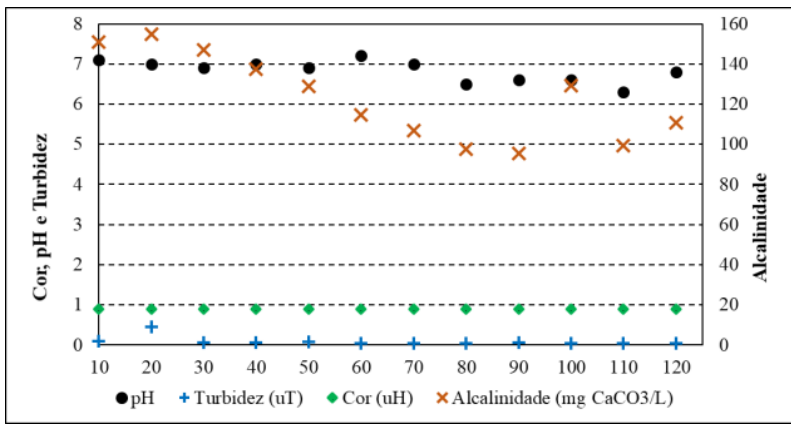

Fonte: (Autores, 2016).

Figura 10. Gráfico das variações de pH, cor, alcalinidade e turbidez do ensaio jar-test com PAC nas concentrações $1 \mathrm{mg} \cdot \mathrm{L}^{-1}, 2 \mathrm{mg} \cdot \mathrm{L}^{-1}$, 3mg.L ${ }^{-1}, 4 m g . L-1,5 m g . L-1$ e $6 m g . L^{-1}, 7 m g . L^{-1}$, $8 \mathrm{mgL}^{-1}, 9 \mathrm{mgL}^{-1}, 11 \mathrm{mgL}^{-1}, 12 \mathrm{mgL}^{-1}$.

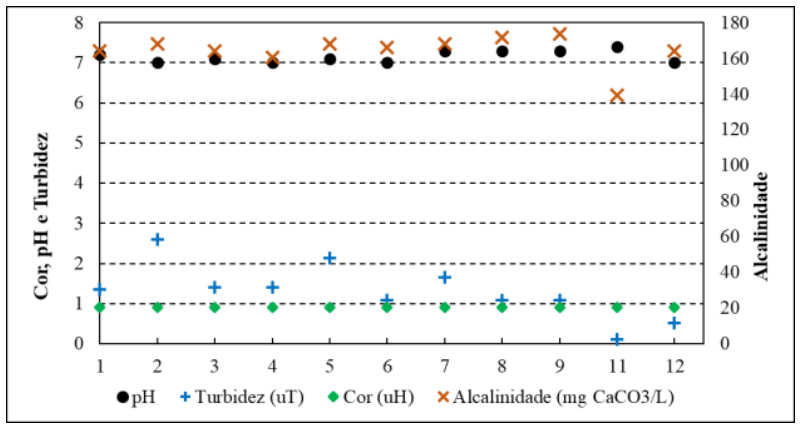

Fonte: (Autores, 2016).

\subsection{Etapa 2}

Estão nesta seção apresentados os resultados das análises físico-químicas, bem como as microbiológicas, realizadas tanto na caracterização da água de estudo, quanto com a água que passou por coagulação, floculação e sedimentação com cada um dos respectivos coagulantes. 


\subsubsection{Resultados físico-químicos}

Os ensaios de bancada realizados nesta etapa utilizaram os mesmos parâmetros de controle operacional descritos na etapa 1 e as dosagens de eficiência nela obtidas. Além disso, os ensaios foram executados em duplicata.

A Tabela 4 apresenta a caracterização da Água de Estudo 4 (AE-4), utilizada nesta etapa da pesquisa.

Tabela 4. Características da Águas de Estudo 4 utilizada nos ensaios da segunda etapa.

\begin{tabular}{cc}
\hline Parâmetros & AE-4 \\
\hline $\mathrm{pH}$ & 7,4 \\
\hline Turbidez (uT) & 17,3 \\
\hline Alcalinidade $\left(\mathrm{mg} \mathrm{CaCO}_{3} \mathrm{~L}^{-1}\right)$ & 207,3 \\
\hline Cor $(\mathrm{uH})$ & 43
\end{tabular}

Fonte: Autores (2016).

A Tabela 5 apresenta os resultados após realização dos ensaios de bancada, em comparação com a água bruta e com os padrões estabelecidos pela Portaria no2914 do Ministério da Saúde (2011).

\subsubsection{Resultados microbiológicos}

Os parâmetros microbiológicos analisados foram coliformes totais, e-coli e bactérias heterotróficas. A Figura 11 apresenta uma placa com colônias formadas de coliformes totais, E-coli e bactérias heterotróficas.
Figura 11. Placa petri com colônias formadas com água bruta.

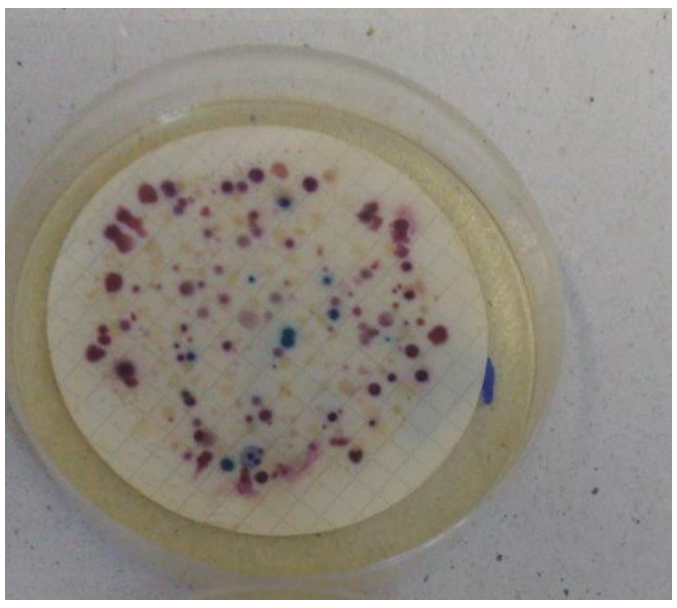

Fonte: (Autores, 2016).

A Figura 12 apresenta os resultados das contagens de unidades formadoras de colônias para a água bruta e para água tratada com os três coagulantes estudados.

Figura 12. Unidades formadoras de colônias com água bruta e agua pós ensaio de bancada com os coagulantes cloreto férrico, sulfato de alumínio e policloreto de alumínio.

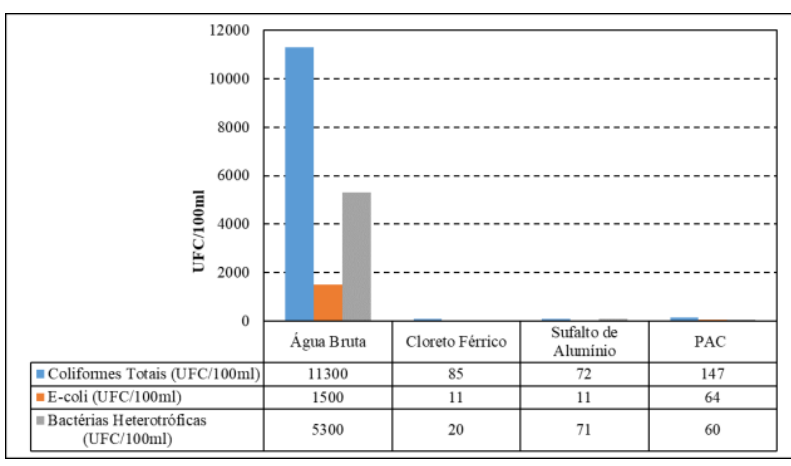

Fonte: (Autores, 2016). 
Tabela 5. Resultados dos ensaios físico-químicos da água bruta e da água tratada com as concentrações de 48mg.L-1 de cloreto férrico, 70mg.L de Sulfato de Alumínio e 10mg.L de PAC, e valores máximos permitidos pela Portaria no 2914/2011.

\begin{tabular}{|c|c|c|c|c|c|c|c|c|}
\hline \multirow{2}{*}{ Parâmetros } & \multirow{2}{*}{$\begin{array}{l}\text { Água } \\
\text { Bruta }\end{array}$} & \multicolumn{2}{|c|}{ Cloreto Férrico } & \multicolumn{2}{|c|}{$\begin{array}{l}\text { Sulfato de } \\
\text { Alumínio }\end{array}$} & \multicolumn{2}{|c|}{ PAC } & \multirow[t]{2}{*}{$\begin{array}{c}\text { Padrão de } \\
\text { Potabilidade }\end{array}$} \\
\hline & & $\begin{array}{c}\text { Amostra } \\
1 \\
\end{array}$ & $\begin{array}{c}\text { Amostra } \\
2 \\
\end{array}$ & $\begin{array}{c}\text { Amostra } \\
1 \\
\end{array}$ & $\begin{array}{c}\text { Amostra } \\
2 \\
\end{array}$ & $\begin{array}{c}\text { Amostra } \\
1 \\
\end{array}$ & $\begin{array}{c}\text { Amostra } \\
2 \\
\end{array}$ & \\
\hline $\begin{array}{l}\text { Concentração } \\
\left(m g . L^{-1}\right)\end{array}$ & - & 48 & 48 & 70 & 70 & 10 & 10 & - \\
\hline $\mathrm{pH}$ & 7,4 & 6,6 & 6,6 & 7,3 & 7,3 & 7,7 & 7,6 & 6,0 a 9,5 \\
\hline $\begin{array}{l}\text { Alcalinidade (mg } \\
\mathrm{CaCO}_{3} \cdot \mathrm{L}^{-1} \text { ) }\end{array}$ & 207,3 & 78,28 & 78,5 & 93,73 & 94 & 178,19 & 176,13 & - \\
\hline Dureza (mg. L $^{-1}$ ) & 95,7 & 96,8 & 97 & 100,1 & 100,1 & 102,3 & 102,3 & 500 \\
\hline Condutividade $(\mu S)$ & 254 & 308 & 308 & 283 & 283 & 291 & 295 & - \\
\hline Cor (uH) & 43 & 6 & 5,8 & 5 & 5 & 7 & 6,8 & 15 \\
\hline Turbidez (uT) & 17,3 & 0,06 & 0,05 & 0,22 & 0,26 & 0,89 & 0,84 & 0,5 e $1^{*}$ \\
\hline $\begin{array}{l}\text { Sólidos Totais } \\
\left(\mathrm{mg} \cdot \mathrm{L}^{-1}\right)\end{array}$ & 310 & 174 & 178 & 126 & 124 & 206 & 204 & 1000 \\
\hline $\begin{array}{l}\text { Nitrato (mg. } \mathrm{L}^{-1} \\
\left.\mathrm{NO}_{3}-\mathrm{N}\right)\end{array}$ & 7,1 & 2,9 & 2,8 & 4,5 & 4,5 & 3,2 & 3,2 & 10 \\
\hline Nitrito (mg. $\mathrm{L}^{-1}$ ) & 0,03 & 0,01 & 0,01 & 0 & 0 & 0 & 0 & 1 \\
\hline Fósforo (mg. $\mathrm{L}^{-1}$ ) & 0,12 & 0,11 & 0,11 & 0,008 & 0,008 & 0,03 & 0,03 & - \\
\hline
\end{tabular}

Fonte: (Autores, 2016; BRASIL, 2011)

\section{DISCUSSÃO}

A discussão dos resultados está organizada de acordo com as etapas estabelecidas no item 3.

\subsection{Etapa 1}

\subsubsection{Cloreto Férrico}

No primeiro ensaio com cloreto férrico, apresentado na Figura 4, os pontos que obtiveram maior remoção de cor e turbidez foram nas contrações de $30 \mathrm{mg}^{-L^{-1}}$, $40 \mathrm{mg} \cdot \mathrm{L}^{-1}$ e $50 \mathrm{mg} \cdot \mathrm{L}^{-1}$. A remoção de cor foi de cerca de 95,7\% nas três concentraçãoes, já a turbidez teve $94,2 \%$ de remoção na concentração de $30 \mathrm{mg} \cdot \mathrm{L}^{-1}$, e cerca de $95 \%$ no jarro com $40 \mathrm{mg} \cdot \mathrm{L}^{-1}$, assim como $95,23 \%$ na dosagem de $50 \mathrm{mg} \cdot \mathrm{L}^{-1}$. Nota-se que a partir dessas concetrações os valores de cor aumentaram, indicando que o coagulante não apresentava eficiência alguma de tratamento quando não se encontra na faixa de coagulação.

Houve redução de alcalinidade e pH em função do aumento das concentrações de cloreto férrico, podendo-se inferir que este coagulante possui a tendência de reduzir a alcalinidade da água.

Como constatou-se que a faixa ótima de coagulação se encontrava entre as 
concentrações de $20 \mathrm{mg} \cdot \mathrm{L}^{-1}$ a $50 \mathrm{mg} \cdot \mathrm{L}^{-1}$, foi realizado um outro ensaio com concentrações intermediárias as investigadas anteriormente. O segundo ensaio (Figura 5) foi executado com as concentrações de $25 \mathrm{mg} . \mathrm{L}^{-1}, \quad 35 \mathrm{mg} . \mathrm{L}^{-1}, \quad 45 \mathrm{mg} . \mathrm{L}^{-1}, \quad 47,5 \mathrm{mg} . \mathrm{L}^{-1}$, $53,5 \mathrm{mg} \cdot \mathrm{L}^{-1}$ e $55 \mathrm{mg} \cdot \mathrm{L}^{-1}$.

Quanto a remoção de cor, todas as concentrações, com excessão da $55 \mathrm{mg} \cdot \mathrm{L}^{-1}$, obtiveram remoção de $95,7 \%$. Assim como a cor residual, a turbidez residual foi baixa, com valores próximos de zero, sendo as concentrações de $47,5 \mathrm{mg} \cdot \mathrm{L}^{-1}$ e $52,2 \mathrm{mg} \cdot \mathrm{L}^{-1}$ as mais eficientes, com $99,6 \%$ de remoção.

Os valores de $\mathrm{pH}$ para as águas deste ensaio reduziram, mantendo o mesmo comportamento que o ensaio anterior, inversamente proporcinal a dosagem do cloreto férrico.

A Figura 13 mostra a água efluente do ensaio, evidenciando a baixa eficiência da amostra do jarro 6 (55mg. $\left.\mathrm{L}^{-1}\right)$.

Figura 13. Água efluente do terceiro ensaio jar-test.

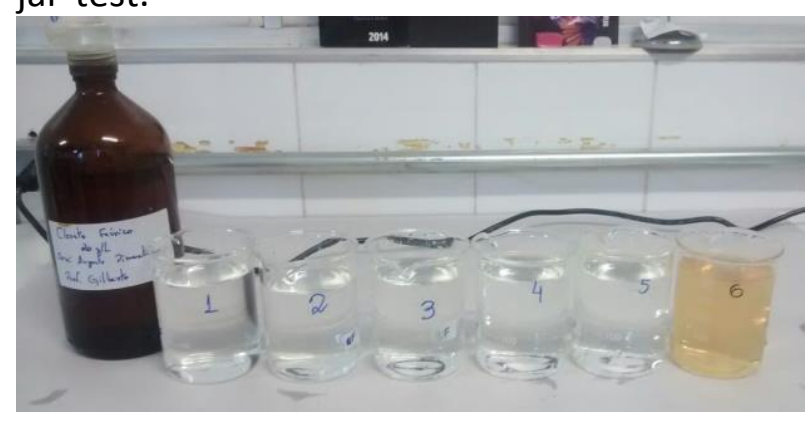

Fonte: (Autores, 2016).

Verificou-se que na dosagem de $47,5 \mathrm{mg} \cdot \mathrm{L}^{-1}$ houve remoção de cor e baixa variação de $\mathrm{pH}$ e alcalinidade, sendo adotada como a mais eficiente neste ensaio. Com base nisso, realizou-se mais um ensaio com concentrações mais próxima a esta para melhor determinação do comportamento do coagulante nesta faixa. O terceiro ensaio (Figura 6) foi realizado incluindo as concentrações de $47 \mathrm{mg} . \mathrm{L}^{-1}, 48 \mathrm{mg} . \mathrm{L}^{-1}, 49 \mathrm{mg} . \mathrm{L}^{-}$ ${ }^{1}, 50 \mathrm{mg} \cdot \mathrm{L}^{-1}, 51 \mathrm{mg} \cdot \mathrm{L}^{-1}, 52 \mathrm{mg} \cdot \mathrm{L}^{-1}, 53 \mathrm{mg} \cdot \mathrm{L}^{-1}$.

Nele constatou-se rápida sedimentação em comparação aos ensaios anteriores, para todas as concentrações, comprovando a formação de flocos mais densos.

Os valores de cor residual para todas as concentrações foram abaixo de $1 \mathrm{uH}$, com eficiência de $95,7 \%$. A turbidez foi o fator determinante na escolha da melhor eficência de coagulação, floaculação e sedimentação. Apesar de todos os valores serem baixos, o jarro 2, com concentração de $48 \mathrm{mg} \cdot \mathrm{L}^{-1}$, apresentou turbidez de 0,07uT 99,7\% de remoção. $\mathrm{O}$ valor de $\mathrm{pH}$ ficou em 6,4 e a alcalinidade em $36,3 \mathrm{mg} \quad \mathrm{CaCO}_{3} \mathrm{~L}^{-1}$, demonstrando a maior eficiência do coagulante em estudo.

\subsubsection{Sulfato de Alumínio}

Durante a realização do primeiro ensaio, observou-se que as partículas formadas ao fim do Tsed (8 minutos) ainda não haviam se sedimentado, logo, foi adotado para este coagulante o Tsed de 16 
minutos, indicando, portanto, que elas eram menos densas.

A Figura 7 apresenta os resultados do primeiro ensaio realizado com o sulfato de alumínio. Os valores de cor residual neste ensaio foram pequenos na maioria dos jarros, com eficiência de remoção de cerca de $96,1 \%$, exceto na concentração de $10 \mathrm{mg} \cdot \mathrm{L}^{-1}$. Quanto a remoção de turbidez as melhores eficiências foram com $60 \mathrm{mg} \cdot \mathrm{L}^{-1}$ e $70 \mathrm{mg} \cdot \mathrm{L}^{-1}$ sendo, $92,2 \%$ e $92,7 \%$ respectivamente.

Nesta água, as concentrações de carbonato de cálcio eram altas, assim, a água bruta apresentava uma maior resistência a variação de $\mathrm{pH}$. Em razão disso, os valores deste parâmetro não variaram bruscamente, consequentemente, a alcalinidade não variou sigficativamente.

Vale resaltar que os maiores valores de alcalinidade e $\mathrm{pH}$ foram na concentração de $20 \mathrm{mg} \cdot \mathrm{L}^{-1}$, jarro este que não obteve boa remoção de cor e turbidez, demonstrando que a redução de carbonato de cálcio para desestabilização dos colóides só ocorre nas concentrações mais adequadas das faixas ótimas.

A partir dos dados foi realizado um ensaio refinado para investigação das concentrações próximas a $70 \mathrm{mg} \cdot \mathrm{L}^{-1}$, como apresenta a Figura 8. A remoção de cor se manteve a mesma, de $96,1 \%$, já a turbidez sofreu variação, sendo a melhor eficiência de
91,8\% na dosagem de $62 \mathrm{mg} \cdot \mathrm{L}^{-1}$, com turbidez residual de 1,24uT.

Praticamente toda a faixa de aplicação do coagulante apresentou remoção de cor, deste modo, tomou-se como padrão a melhor eficiência na turbidez. $\mathrm{Na}$ concentração de $70 \mathrm{mg}^{-L^{-1}}$ (Figura 7) a turbidez foi de $1,1 \mathrm{uT}$, se mostrando como mais eficaz no processo de coagulação/floculação e sedimentação para o sulfato de alumínio.

\subsubsection{Policloreto de Alumínio (PAC)}

O tempo de sedimentação necessário a esse coagulante foi menor do que o esperado para padronização do ensaio. Os flocos com 2 minutos e 30 segundos já estavam todos sedimentados.

A Figura 9 apresenta os resultados do primeiro ensaio com PAC, nele constatou-se que em todas as amostras a cor residual foi menor que $1 \mathrm{uH}$, com eficiência de cerca de 95\%. Quanto a turbidez, essa apresentou remoção parecida em todas as provas, sendo as melhores eficiências as concentrações de 60mg. $\mathrm{L}^{-1}, \quad 70 \mathrm{mg} . \mathrm{L}^{-1}, \quad 80 \mathrm{mg} \cdot \mathrm{L}^{-1}, \quad 100 \mathrm{mg} . \mathrm{L}^{-}$ ${ }^{1}, 110 \mathrm{mg} \cdot \mathrm{L}^{-1}$ e $120 \mathrm{mg} \cdot \mathrm{L}^{-1}$, com 99,6\% de remoção.

Os valores de $\mathrm{pH}$ se mantiveram acima de 6,9, mostrando que além da ótima formação de flocos em todos os jarros, não houve elevado consumo de alcalinidade. Ainda assim, é notório que os valores 
diminuíram gradualmente com o aumento da dosagem do coagulante.

Como o PAC apresentou desempenho satisfatório em toda a faixa de concentrações, foram então investigadas as concentrações menores que $10 \mathrm{mg} . \mathrm{L}^{-1}$ como exposto na Figura 10.

Com exceção das duas primeiras concentrações, todas as demais apresentaram a mesma remoção de cor, cerca de $95 \%$

Apesar de ocorrer significativa remoção da turbidez em todos os jarros, sua eficiência foi inferior ao observado no ensaio anterior, estabelecendo o melhor resultado na concentração de $11 \mathrm{mgL}^{-1}$ com $98,9 \%$.

Os valores de $\mathrm{pH}$ não tiveram grandes alterações, comparados ao da água bruta. $\mathrm{A}$ alcalinidade se manteve acima do valor averiguado na água bruta, com exceção da amostra com $11 \mathrm{mg} \cdot \mathrm{L}^{-1}$ de PAC.

Com base nos valores obtidos com os ensaios utilizando o PAC, observa-se que a eficiência de tratamento não varia drasticamente, sendo ela maior que as observadas com cloreto férrico e sulfato de alumínio.

Usando a menor concentração que cumpriu o critério de eficiência, obtida na concentração de $10 \mathrm{mg} \cdot \mathrm{L}^{-1}$, apesar de não apresentar as melhores eficiências do primeiro ensaio, é a menor concentração que apresenta satisfatórias remoções de cor e turbidez.

4.1.4 Comparação entre as melhores eficiências da etapa 1

Para avaliação dos resultados com as diferentes águas de estudo utilizados nesta etapa, foi elaborada uma comparação entre os dados obtidos com as melhores eficiências de coagulação/floculação e sedimentação de cada coagulante, com os valores da água bruta utilizadas em cada ensaio (Figura 14).

Figura 14. Gráfico com comparação entre os parâmetros $\mathrm{pH}$, cor, alcalinidade e turbidez dos ensaios realizados na etapa 1 .

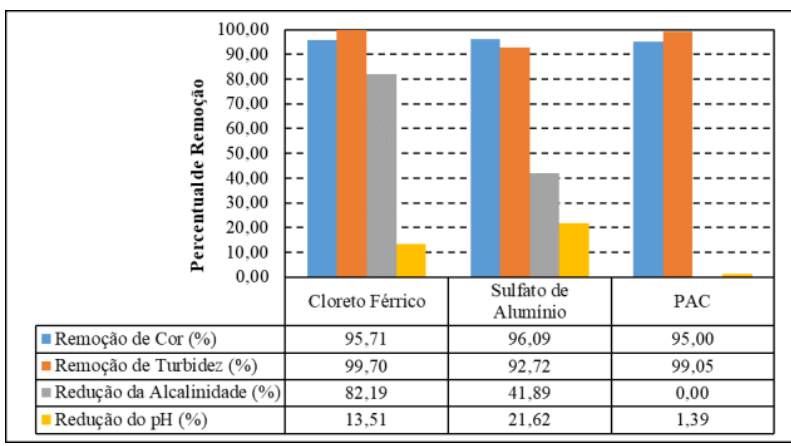

Fonte: (Autores, 2016).

Com base na Figura 14 pode-se observar que a maior remoção de turbidez foi obtida no cloreto férrico, em comparação á agua bruta utilizada. O PAC também apresentou alta porcentagem de remoção, seguido pelo sulfato de alumúnio. Entretanto, quanto a parâmetro de cor, o sulfato de alumínio apresentou maior eficiência, seguido do cloreto férrico e por último do PAC. 
Apesar das diferenças, os valores obtidos de cor e turbidez para todos os coagulantes são adequados para uma ETA de ciclo completo, haja visto que após o processo de coagulação/floculação e sedimentação realizado, passaria por filtração rápida.

Quando se trata da variação de $\mathrm{pH}, \mathrm{o}$ PAC se mostrou o mais eficiente, tendo ele causado uma elevação do pH, e, consequentemente da alcalinidade da água. Fato importante na operação de ETA, visto que reduziria a necessidade de produtos para correção final de $\mathrm{pH}$. O cloreto férrico vem em último nesses quesitos, evidenciando a necessidade de correção final do pH.

\subsection{Etapa 2}

\subsubsection{Análise dos resultados físico-químicos}

Com base na Tabela 5 pode-se observar que, de acordo com o estabelecido na Portaria no 2.914 de 2011 do Ministério da Saúde (BRASIL, 2011), a cor aparente deve ter no máximo $15 \mathrm{uH}$, sendo assim todos os coagulantes estudados atenderam ao padrão. Entretanto, o sulfato de alumínio apresentou a melhor eficiência com $88,4 \%$ de remoção.

Quanto à turbidez, a Portaria referida estipula valores máximos para águas pósfiltração ou pré-desinfecção, sendo o valor máximo permitido de 0,5 uT. Deste modo, o cloreto férrico e sulfato de alumínio atendem o padrão antes mesmo de filtração. Contudo, deve-se complementar que o cloreto férrico apresenta os melhores valores de remoção, com $99,8 \%$.

Os sólidos dissolvidos totais da água atenderam os três casos do padrão de potabilidade, contudo a melhor remoção de $59,4 \%$ ficou com o sulfato de alumínio.

Os valores de $\mathrm{pH}$ estabelecidos na Portaria, no 2.914 (BRASIL, 2011) devem variar de 6 a 9,5. Nesse parâmetro todos os coagulantes atenderam a exigência, sendo que o sulfato de alumínio não apresentou redução significativa. O PAC obteve a melhor eficiência, proporcionando uma elevação de $2,7 \%$. O controle do pH pós coagulação não precisaria ser realizado para nenhum dos coagulantes estudados.

O consumo de alcalinidade pelos coagulantes apresentou comportamento similar ao da primeira etapa da pesquisa, sendo novamente o PAC o que menos consumiu alcalinidade, com $14 \%$.

As concentrações de nitrito e nitrato da água bruta já estão dentro dos requisitos da Portaria, porém, observa-se que o PAC removeu totalmente o nitrito e 54,9\% da concentração de nitrato. Do mesmo modo o fósforo obteve maior eficiência no PAC com 75\% de remoção.

\subsubsection{Análise dos resultados Microbiológicos}


Com base na Figura 15 percebeu-se que os valores de unidades formadoras de colônias obtidos em todos os coagulantes foram substancialmente inferiores aos obtidos com a água bruta. Todos os coagulantes obtiveram significantes resultados quanto à remoção de microrganismos, porém, para uma melhor compreensão das remoções a Figura 16 apresenta o percentual de remoção obtido nos ensaios.

Figura 15. Unidades formadoras de colônias com água bruta e agua pós ensaio de bancada com os coagulantes cloreto férrico, sulfato de alumínio e policloreto de alumínio.

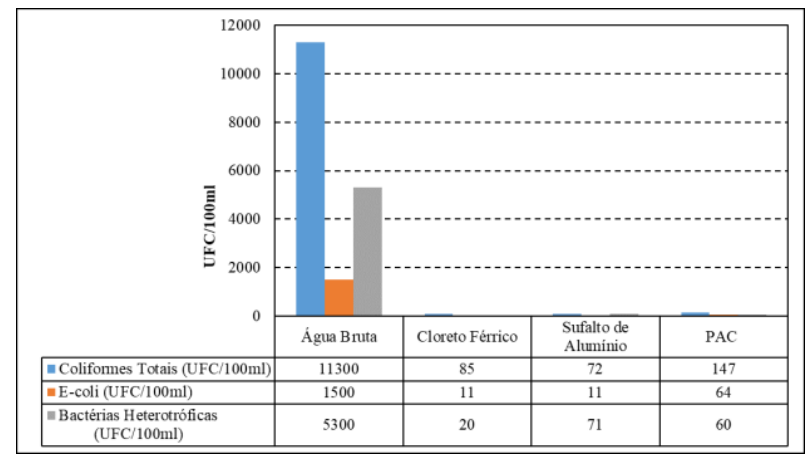

Fonte: (Autores, 2016).
Figura 16. Percentual de remoção de microrganismos com água pós ensaio de bancada com os coagulantes cloreto férrico, sulfato de alumínio e policloreto de alumínio.

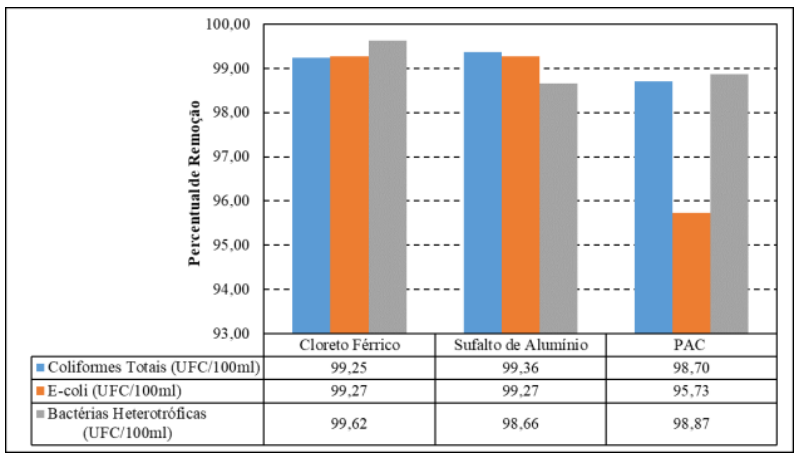

Fonte: (Autores, 2016).

A E-coli, segundo a Portaria no 2.914 (BRASIL, 2011), é o principal parâmetro biológico referente a contaminação da água a ser considerado, devendo haver ausência deste. Averiguou-se que a remoção de E-coli foi igual para o cloreto férrico e para o sulfato de alumínio, seguida pelo PAC.

Os coliformes totais são indicadores da eficiência de tratamento das bactérias do seu grupo, sua maior remoção ocorre no sulfato de alumínio. Já as bactérias heterotróficas foram mais removidas pelo cloreto férrico.

Com base no ensaio microbiológico observa-se uma maior eficiência do sulfato de alumínio nos dois parâmetros indicadores de contaminação fecal. Como todos os coagulantes atenderam ao especificado na portaria quanto aos parâmetros físicoquímicos, os parâmetros microbiológicos foram determinantes para a escolha do 
melhor coagulante. Portanto, o sulfato de alumínio foi identificado como o melhor coagulante para o tratamento de água bruta do Rio Santo Anastácio.

\section{CONCLUSÃO}

\subsection{Etapa 1}

Os ensaios da etapa 1 foram realizados com águas de características distintas para cada respectivo coagulante, logo, obteve-se as maiores eficiências de cada um deles para cada uma de suas águas com suas características particulares, não levando em consideração as concentrações, mas sim as melhores eficiências para cada água utilizada.

Nesta etapa para água com turbidez variando de 9,43uT a 23,5 uT e cor de $18 \mathrm{uH}$ a $23 \mathrm{uH}$ pode-se concluir que:

- A remoção de cor foi eficiente para todos os coagulantes independente das dosagens.

- Quanto a remoção de turbidez, o cloreto férrico obteve os melhores resultados. Já o PAC apesar de não ser o mais eficiente, apresentou eficiência próximas ao cloreto férrico.

- Nesta etapa o sulfato de alumínio obteve as menores eficiências de tratamento.

- Apesar da disparidade dos dados, para água com turbidez variando de 9,43ut a 23,5uT e cor de 18 uH a
23uH, a eficiência de todos os coagulantes atenderam aos padrões estabelecidos pela Portaria no 2914 do Ministério da Saúde.

- Pode-se concluir nesta etapa que o coagulante que obteve a melhor eficiência nesta etapa foi o PAC, apesar de a turbidez ter sido menor que o cloreto férrico, foi com ele apresentada a maior faixa de eficiência de coagulação/floculação e sedimentação e, as menores variações de $\mathrm{pH}$ e alcalinidade.

\subsection{Etapa 2}

Na etapa 2 para água com turbidez 17,3uT e cor de $43 u H$, concluiu-se que:

- Em relação aos parâmetros físicoquímicos todos os coagulantes atenderam as exigências da n 2914 do Ministério da Saúde e podem ser utilizados para ETA's de ciclo completo.

- Em relação aos parâmetros biológicos o cloreto férrico e sulfato de alumínio apresentaram remoções similares, e o PAC a pior eficiência, todavia para processo de ciclo completo todos poderiam ser utilizados.

Com base nos comportamentos acima descritos, a etapa 2 desta pesquisa foi o ponto relevante para decisão de qual o melhor coagulante, visto que os parâmetros 
físico-químicos de ambas as etapas atenderam os critérios da Portaria № 2914. Portanto, devido a melhor eficiência da remoção de organismos de contaminação fecal, o sulfato de alumínio foi o coagulante com a melhor eficiência.

\section{REFERÊNCIAS}

APHA. Standard Methods for the Examination of Water and Wastewater. 22 ed. Washington, 2012.

BAUMANN, E. R. Water quality and treatment: a handbook of public water supplies. 3. ed. New York: McGraw-Hill, 1971.

BERNARDO, L; DANTAS, A. B. Métodos e técnicas de tratamento de água. 2 ed. São Carlos: Editora Rima, 2005.

BERNARDO, L. et al. Ensaios de tratabilidade de água e dos resíduos gerados em estações de tratamento de água. São Carlos: Editora Rima, 2002.

BRASIL. Ministério da Saúde. Portaria no 2.914, de 12 de dezembro de 2011.Diário Oficial [da] República Federativa do Brasil. Poder Executivo, Brasília, DF, 14 dez. 2011. Disponível em: <http://bvsms.saude.gov.br/bvs/saudelegis/g $\mathrm{m} / 2011 /$ prt2914 1212 2011.html>. Acesso em: 16 mai. 2016.

CETESB. Relatório de qualidade das águas interiores do Estado de São Paulo. São Paulo: CETESB, 1991.

DIBIESO, E. P. Planejamento ambiental e gestão dos recursos hídricos: estudo aplicado à bacia hidrográfica do manancial alto curso do rio santo Anastácio, São Paulo/Brasil. 2013. 283 f. Tese (Doutorado em Geografia) Faculdade de Ciências e Tecnologia da Unesp, Presidente Prudente-SP, 2013.

MATOS, R. J. Estudo biogeográfico do alto curso do rio Santo Anastácio: análise comparativa da qualidade da água em canais de terceira ordem. 2014. 224 f. Tese (Doutorado em Geografia) - Faculdade de Ciências e Tecnologia da Unesp, Presidente Prudente, 2014.

MERCK. $\quad$ ChromoCult ${ }^{\circledR}$ Coliform Agar. Disponível em: <http://www.proanálise.com.br/files/uploads/catalogos/Merc k_Chromocult_coliform.pdf $>$. Acesso em: 20 jun. 2013.

RICHTER, C. A.; AZEVEDO NETO, J. M. Tratamento de Água: tecnologia atualizada. 7 ed. São Paulo: Edgard Blücher, 2007. 332 p.

SANTANA, A. T. Estudo da qualidade da água para consumo hmano em assentamentos de Teodoro Sampaio-SP. 2014. 101 f. Dissertação (Mestrado) - Universidade do Oeste Paulista, Presidente Prudente-SP, 2014.

SÃO PAULO (Estado). Departamento de Águas e Energia Elétrica. Instrução Técnica DPO no006. São Paulo, 2012. Disponível em: http://www.daee.sp.gov.br/outorgaefiscaliza cao/IT_DPO_006_10112011.pdf. Acesso em 12 out 2016.

SUDO, H. Bacia do Alto Santo Anastácio: estudo geomorfológico. 1980. 235 f. Tese (Doutorado em Geografia) - Departamento de Geografia da FFLCH, Universidade de São Paulo, São Paulo.

VANACÔR, R. N. Avaliação do coagulante orgânico veta organic utilizado em uma estação de tratamento de água para abastecimento público. 2005. $188 \mathrm{f}$. Dissertação (Mestrado em Engenharia) Universidade Federal do Rio Grande do Sul, Porto Alegre-RS, 2005. 